\title{
Mexico's Integration into NAFTA Markets: A View from Sectoral Real Exchange Rates
}

\author{
Rodolphe Blavy and Luciana Juvenal
}

\begin{abstract}
The authors use a threshold autoregressive model to confirm the presence of nonlinearities in sectoral real exchange rate dynamics across Mexico, Canada, and the United States for the periods before and after the North American Free Trade Agreement (NAFTA). Although trade liberalization is associated with reduced transaction costs and lower relative price differentials among countries, the authors find, by using estimated threshold bands, that Mexico still faces higher transaction costs than its developed counterparts. Other determinants of transaction costs are distance and nominal exchange rate volatility. The authors' results show that the half-lives of sectoral real exchange rate shocks, calculated by Monte Carlo integration, imply much faster adjustment in the post-NAFTA period. (JEL F31, F36, F41)
\end{abstract}

Federal Reserve Bank of St. Louis Review, September/October 2009, 91(5, Part 1), pp. 441-64.

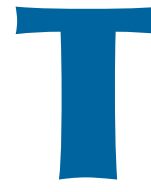

he analysis of relative price differentials across countries and sectors offers a way to evaluate the degree of market integration. The law of one price (LOOP) states that identical goods should sell for the same price across countries when prices are expressed in a common currency. Evidence has shown, however, that prices of goods fail to fully equalize between countries, indicating that markets are not perfectly integrated.

Prices of homogeneous goods tend to differ across countries because the presence of transaction costs—such as transport costs and (explicit or implicit) trade barriers-limits price arbitrage. The study of the LOOP among members of the North American Free Trade Agreement (NAFTA) is of particular interest because it allows an assessment of whether regional trade liberalization results in faster price convergence and smaller price differentials across countries and in greater market integration.

This paper focuses on three issues. First, we assess the degree of market integration between the United States, Mexico, and Canada by analyzing the validity of the LOOP between the countries. Second, we determine whether markets became more integrated, with reduced transaction costs, after the introduction of NAFTA. Finally, we analyze whether transaction costs are related to economic determinants.

Our study focuses on the role of transaction costs in modeling deviations from the LOOP. Several theoretical studies (see Dumas, 1992; Sercu and Raman, 1995; and O'Connell, 1998) show that because of transaction costs, it may not be profitable to arbitrage away relative price differences across countries when the marginal costs of arbitrage exceed the marginal benefits. This

Rodolphe Blavy is an economist at the International Monetary Fund and Luciana Juvenal is an economist at the Federal Reserve Bank of St. Louis. The authors thank the staff of the Banco de Mexico for their helpful comments, Steven Phillips for his contributions at various stages of preparation of this paper, and Roberto Benelli, Roberto Garcia-Saltos, David J. Robinson, Lucio Sarno, and seminar participants at the International Monetary Fund and at the Latin American and Caribbean Economic Association 2007 conference for comments. Volodymyr Tulin and Douglas Smith provided research assistance.

(C) 2009, The Federal Reserve Bank of St. Louis. The views expressed in this article are those of the author(s) and do not necessarily reflect the views of the Federal Reserve System, the Board of Governors, or the regional Federal Reserve Banks. Articles may be reprinted, reproduced, published, distributed, displayed, and transmitted in their entirety if copyright notice, author name(s), and full citation are included. Abstracts, synopses, and other derivative works may be made only with prior written permission of the Federal Reserve Bank of St. Louis. 
situation generates a band of no trade where prices in two locations fail to equalize. Outside this threshold band, arbitrage is profitable and the sectoral real exchange rate (SRER) can become mean-reverting. This dynamic implies nonlinearities in SRERs and is well captured by using a threshold autoregressive (TAR) model for each sectoral relative price (see Tong, 1990; and Hansen, 1996 and 1997). The TAR model allows for deviations from the LOOP to exhibit unit root behavior inside the threshold band and to become meanreverting outside the band. If there is no mean reversion in the outer regime, relative prices fail to equalize between countries-a sign of weak market integration. In this way, the estimated threshold bands provide a measure of transaction costs.

The empirical methodology analyzes dynamics in relative price adjustment and innovates by taking the perspective of an emerging marketMexico. ${ }^{1}$ Motivated by the previous literature, we investigate the presence of threshold-type nonlinearities in deviations from the LOOP by comparing the monthly real U.S. dollar/Mexican peso exchange rate, U.S. dollar/Canadian dollar exchange rate, and monthly real Mexican peso/ Canadian dollar exchange rate over 1980-2006.

Nonlinearities are captured using a selfexciting threshold autoregressive (SETAR) model. More precisely, we estimate SETAR models for each SRER for the pre- and post-NAFTA periods. This estimation gives a measure of transaction costs (threshold band) and the autoregressive parameter outside the band. We determine whether deviations from the LOOP show mean-reverting properties by testing whether the nonlinear specification is superior to a nonstationary model for each subsample. This requires testing whether the autoregressive process outside the band is significantly different from the random walk observed inside the band. We also test whether the threshold bands are significantly wider for each SRER in the pre- and post-NAFTA periods,

1 There is now an established literature on the nonlinear behavior of SERSs for developed markets (see Obstfeld and Taylor, 1997; Imbs et al., 2003; Sarno, Taylor, and Chowdhury, 2004; and Juvenal and Taylor, 2008). thus allowing assessment of whether NAFTA led to higher market integration.

The results show that transaction costs are larger for the Mexico-U.S. and Mexico-Canada country pairs than for the Canada-U.S. pair, thus suggesting a higher degree of market integration between the United States and Canada. We also find that NAFTA significantly reduced transaction costs and price differentials between the United States and Mexico, although this was not uniform across sectors. Finally, our estimated transaction costs are negatively related to trade liberalization, commonly shared geographic borders, and lower exchange rate volatility.

To measure the speed of mean reversion, we use generalized impulse response functions to compute the half-life of exchange rates, which is the time it takes for 50 percent of the effect of a shock to dissipate (see Koop, Pesaran, and Potter, 1996). We find that half-lives are substantially reduced after the introduction of NAFTA, especially for the Mexico-U.S. country pair. This implies that reduced arbitrage costs were accompanied by faster adjustments in price differentials.

The remainder of the paper is organized as follows. The next section reviews theoretical considerations on nonlinear dynamics in SRERs and presents the corresponding econometric methodology. The following sections first discuss the results and then provide a battery of robustness tests. The last section concludes.

\section{NONLINEARITIES: MOTIVATION AND EMPIRICAL FRAMEWORK}

According to the LOOP, similar goods should be priced the same across countries when prices are expressed in a common currency. At the aggregate level, the LOOP translates into purchasing power parity. The LOOP is based on the assumption of frictionless goods arbitrage-an environment in which there are no impediments to trade or transaction costs that would prevent perfect arbitrage.

Ample empirical evidence (Isard, 1977; Richardson, 1978; and Giovannini, 1988) suggests 
that relative prices do not converge, or do so only with a very long-term horizon, and that price differentials are persistent. These studies also find that relative price differentials are significant and highly correlated with exchange rate movements.

One reason that prices of homogeneous commodities may not be the same across different countries is the existence of transaction costs arising from transport costs, tariffs, and nontariff barriers. ${ }^{2}$ A number of theoretical papers suggest the importance of transport and trade barriers in creating price differences between countries (e.g., Dumas, 1992; Sercu and Raman, 1995; and O'Connell, 1998). The models described in such studies have incorporated different assumptions regarding the nature of trade costs. Overall, price differences driven by transaction costs can be expressed as $S^{i} P_{j}^{i}=P_{j}^{R}+A_{j}$, where $S^{i}$ is the nominal exchange rate between country i's currency and the reference country, $P_{j}^{i}$ is the price of good $j$ in country $i, P_{j}^{R}$ is the price of good $j$ in the reference country, and $A_{j}$ is the marginal transaction cost. In particular, $A_{j}$ shows the minimum price difference that makes arbitrage profitable between country $i$ and the reference country. In the presence of perfectly competitive markets and constant returns to scale technology and in the absence of sellers' pricing power, price differences that are higher than the transaction costs will be arbitraged. Thus,

$$
-A_{j} \leq S^{i} P_{j}^{i}-P_{j}^{R} \leq A_{j} .
$$

In this framework, transaction costs generate two regimes: (i) when price differentials are smaller than transaction costs, there is a regime of no arbitrage described by equation (1) and (ii) when price differences exceed transaction costs, arbitrage is profitable and equation (1) does not hold. This implies that price differentials behave in a nonlinear fashion. Price differentials follow a nonstationary process within the transaction costs band (or threshold band), and outside the

2 Heckscher (1916) first pointed out the possibility of nonlinearities in relative prices in the presence of trade frictions. In the case of Mexico, González and Rivadeneyra (2004) investigate the LOOP between Mexican cities and provide empirical evidence that transactions costs (including tariff and nontariff barriers) explain departures from the LOOP. band they are mean reverting toward the band because of arbitrage effects.

The condition expressed in equation (1) can be written in terms of each SRER as

$$
1-\frac{A_{j}}{P_{j}^{R}} \leq \frac{S^{i} P_{j}^{i}}{P_{j}^{R}} \leq 1+\frac{A_{j}}{P_{j}^{R}},
$$

where

$$
\frac{S^{i} P_{j}^{i}}{P_{j}^{R}}
$$

is the SRER between country i's currency and the reference country for good $i$. Condition (2) implies that transaction cost bands and nonlinearities are both good-specific and country pair-specific.

Based on the previous theoretical framework, a number of empirical studies analyze the nonlinear nature of deviations from the LOOP in terms of a TAR model (e.g., Tong, 1990). The TAR model allows for the presence of a threshold band within which arbitrage is not profitable. Consequently, deviations from the LOOP follow a unit root process. Outside the band the process can become mean-reverting.

Recent contributions that use this model to analyze SRER dynamics of developed markets include Obstfeld and Taylor (1997), Sarno, Taylor, and Chowdhury (2004), Imbs et al. (2003), and Juvenal and Taylor (2008). In particular, Obstfeld and Taylor (1997), who used disaggregated data on clothing, food, and fuel, find evidence of nonlinearities in a sample of 32 locations. Sarno et al. (2004) provide support for nonlinear mean reversion with considerable cross-country and sectoral heterogeneity. They use annual price data interpolated into quarterly data for nine sectors and quarterly data on five exchange rates vis-à-vis the U.S. dollar. Juvenal and Taylor (2008) study the presence of nonlinearities in deviations from the LOOP for 19 sectors in 10 European countries and find significant evidence of threshold adjustment with transaction costs varying considerably across sectors and countries.

\section{Empirical Framework}

Data. We use disaggregated monthly data on consumer price indices (CPIs) for 18 sectors from 
January 1980 to December 2006 for Mexico, the United States, and Canada. Data on CPIs were obtained from the Bank of Mexico, the U.S. Bureau of Labor Statistics, and Statistics Canada. The sectors analyzed are bread, meat, fish, dairy, fruits, veg (vegetables), nonalco (nonalcoholic beverages), alco (alcoholic beverages), tobac (tobacco), clothw (women's clothing), clothm (men's clothing), foot (footwear), fuel, furniture, medic (medication), vehicles, gasoline, and photo (photographic equipment). Table 1 lists the sectors analyzed in this study and the description of the category for each country. Monthly nominal exchange rates are period averages from International Financial Statistics of the International Monetary Fund.

Model. We model deviations from the LOOP using a SETAR model for each sectoral exchange rate to analyze the patterns in relative price convergence. More precisely, we investigate the presence of nonlinearities in deviations from the LOOP using a threshold-type model with two regimes.

Our model process involves four steps. First, we estimate TAR models for each SRER. Second, we explore the validity of the nonlinear threshold model with respect to a null hypothesis of unit root process. This allows us to test for the existence of some degree of price convergence as opposed to no price convergence at all. ${ }^{3}$ Third, when we find evidence that a nonlinear specification is superior to a nonstationary model, we determine whether price convergence is characterized by an asymmetric threshold adjustment consistent with arbitrage arguments. That is, we test whether a nonlinear model fits the data better than a stationary linear one. Finally, when we find evidence of nonlinear price convergence in

3 A failure to reject the unit root hypothesis implies that deviations from the LOOP are a uniform unit root process and, thus, prices in two locations are disconnected. This test allows identification of any difference in the autoregressive parameters between the inner band and the outer band regimes. This test is an important addition to the methodology generally used in the literature. Earlier studies directly test for nonlinearity with respect to a linear model but do not determine whether the outer regime is nonstationary. An exception is found in Peel and Taylor (2002), who present a procedure to test for unit root to study covered interest parity. We use the procedure developed by Enders and Granger (1998) to test for the null hypothesis of nonstationarity against an alternative of stationarity with threshold adjustment. the pre- and post-NAFTA periods, we determine whether the size of the threshold band is equal in both periods.

The existence of transaction costs, in the form of transport costs or trade barriers, is one explanation for the lack of price convergence. As described previously, frictions to trade imply the presence of significant nonlinearities in SRER dynamics. That is, transaction costs generate a band in which the marginal costs of arbitrage exceed the marginal benefit. Within this band, there is a zone of no trade and consequently prices in two locations fail to equalize. Outside this band, arbitrage is profitable and the SRER can become mean-reverting. Empirically, this pattern is described by a TAR model, which was originally popularized by Balke and Fomby (1997) in the context of testing for purchasing power parity and the LOOP.

Let $x_{j t}^{i}$ be the deviation from the LOOP for a sector $j$ in country $i$ at time $t$, defined as follows:

$$
x_{j t}^{i}=s_{t}^{i}+p_{j t}^{i}-p_{j t}^{R},
$$

where $s_{t}^{i}$ is the logarithm of the nominal exchange rate between country i's currency and the reference country, $p_{j t}^{i}$ is the logarithm of the price of good $j$ in country $i$ at time $t$, and $p_{j t}^{R}$ is the logarithm of the price of good $j$ in the reference country at time $t$.

A simple three-regime TAR model may be written as

$$
\begin{gathered}
q_{j t}^{i}=\alpha q_{j t-1}^{i}+\varepsilon_{j t}^{i} \text { if }\left|q_{j t-d}^{i}\right| \leq \kappa \\
q_{j t}^{i}=\kappa(1-\rho)+\rho q_{j t-1}^{i}+\varepsilon_{j t}^{i} \text { if } q_{j t-d}^{i}>\kappa \\
q_{j t}^{i}=-\kappa(1-\rho)+\rho q_{j t-1}^{i}+\varepsilon_{j t}^{i} \text { if } q_{j t-d}^{i}<-\kappa \\
\varepsilon_{j t}^{i} \sim N\left(0, \sigma^{2}\right),
\end{gathered}
$$

where $q_{j t}^{i}$ is the demeaned component of the relative price difference, $x_{j t}^{i}$, given by $x_{j t}^{i}=c_{j}^{i}+q_{j t}^{i}\left(q_{j t}^{i}\right.$ is estimated as an ordinary least squares [OLS] residual), $\kappa$ is the threshold parameter, ${ }^{4}$ and $q_{j t-d}^{i}$ is the threshold variable for sector $j$ and country $i$. The parameter $d$ accounts for the delay with

\footnotetext{
${ }^{4}$ Note that $\kappa$ is country and sector specific.
} 
Blavy and Juvenal

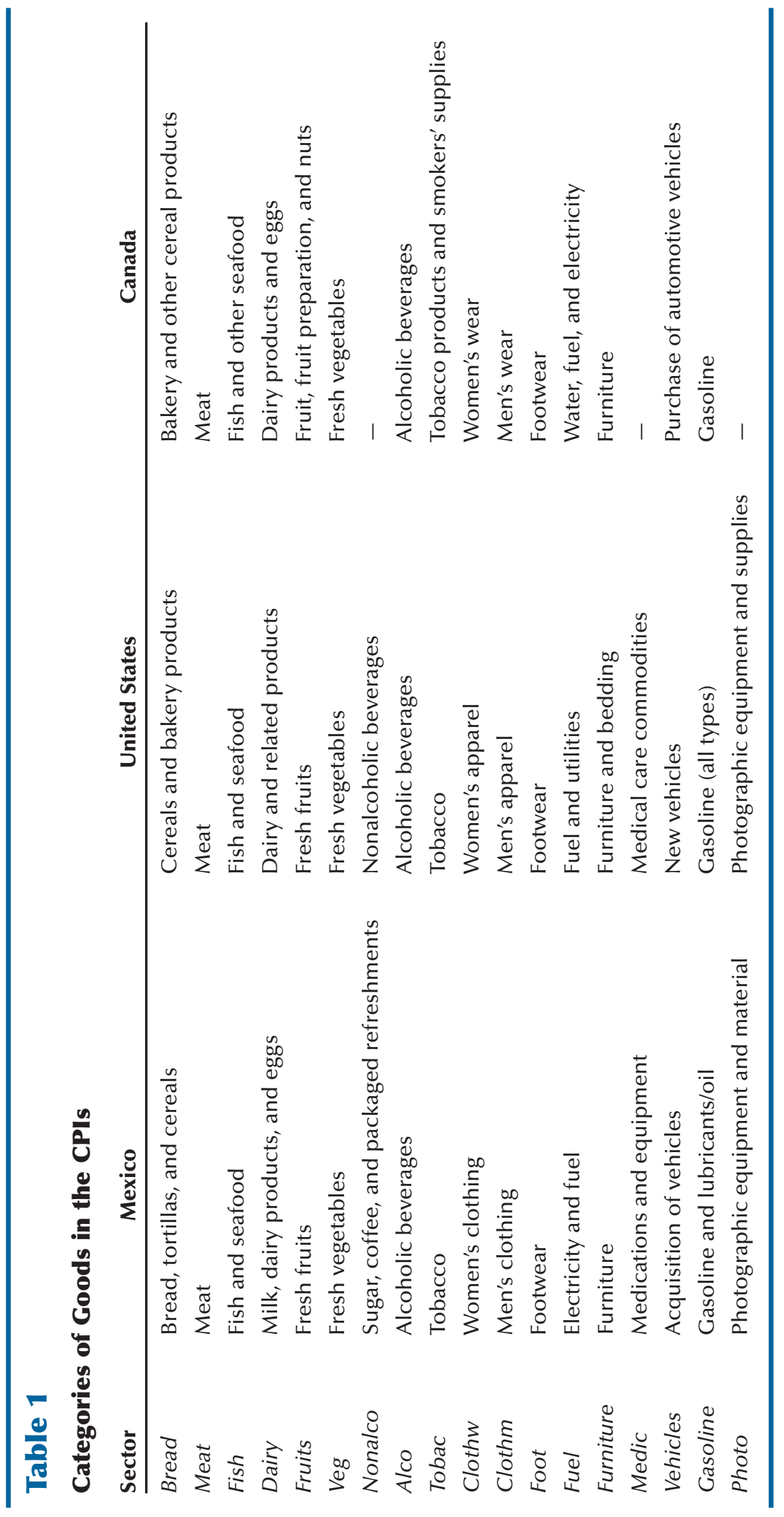




\section{Figure 1}

\section{Footwear Real Exchange Rate and Threshold Bands}

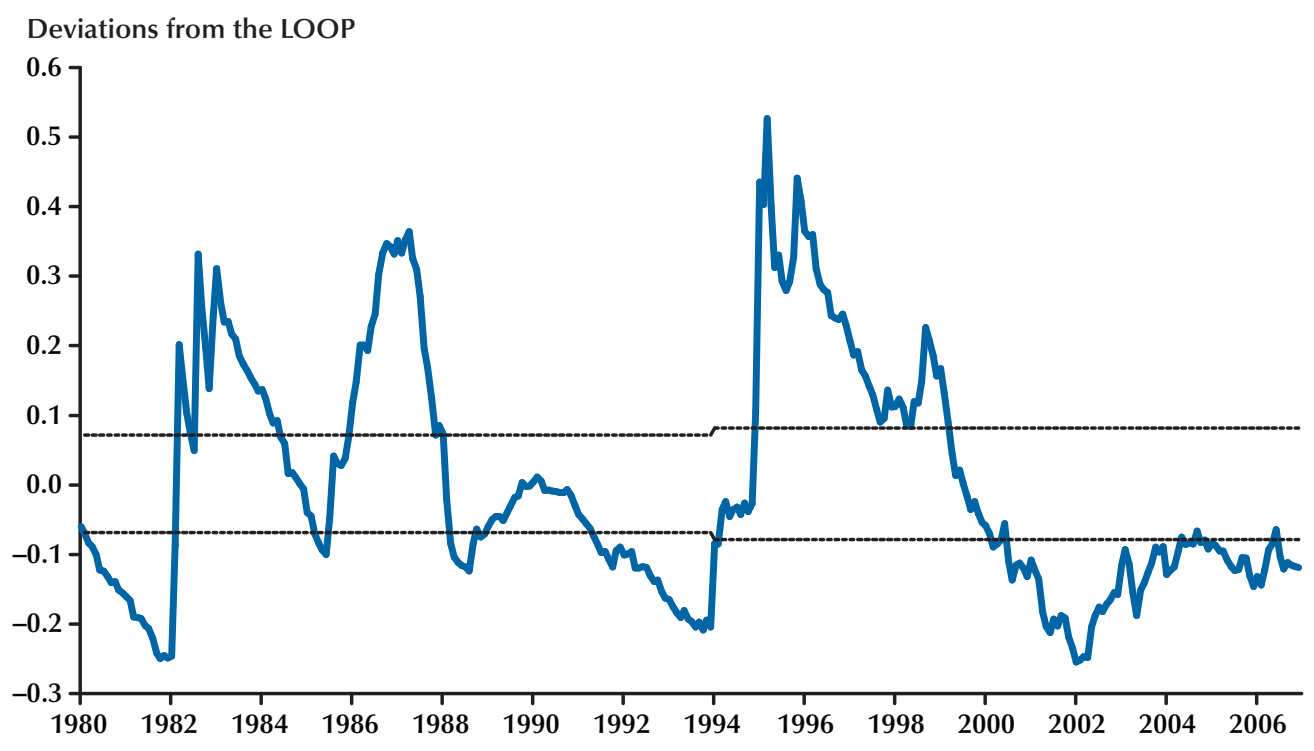

which economic agents react to real exchange rate deviations.

Hereafter, we restrict the value of $\alpha$ to unity, so that, inside the band, deviations from the LOOP are persistent and follow a random walk. ${ }^{5}$ Outside the band, when $\left|q_{j t-d}^{i}\right|>\kappa$, the process becomes mean-reverting as long as $\rho<1$. The model described is a TAR $(1,2, d)$, where 1 is the autoregressive order, 2 is the number of thresholds, and $d$ is the delay parameter. Further, because the threshold variable is assumed to be the lagged dependent variable, the model is called SETAR $(1,2, d)$ with the given parameters.

Figure 1 shows an example of the estimated model. The graph contains the time series for $q_{j t}^{i}$ (solid line), which represents the demeaned real exchange rate between Mexico and the United States for the footwear sector and the estimated $\kappa$ (dashed lines).

Estimation. Using indicator functions $1\left(q_{j t-d}^{i}>\kappa\right)$ and $1\left(q_{j t-d}^{i}<-\kappa\right)$, which take the

5 This restriction is widely used in the literature; see Obstfeld and Taylor (1997), Imbs et al. (2003), Sarno, Taylor, and Chowdhury (2004), and Juvenal and Taylor (2008). value of 1 when the inequality is satisfied, the model in equations (4) through (7) can be simplified to equation (8):

$$
\begin{aligned}
& \Delta q_{j t}^{i}=\left[(\rho-1)\left(q_{j t-1}^{i}-\kappa\right)\right] 1\left(q_{j t-d}^{i}>\kappa\right) \\
& +\left[(\rho-1)\left(q_{j t-1}^{i}+\kappa\right)\right] 1\left(q_{j t-d}^{i}<-\kappa\right)+\varepsilon_{j t}^{i} .
\end{aligned}
$$

Note that the model in equation (8) is assumed to be symmetric. Thus, deviations from the LOOP outside the threshold band are the same regardless of whether prices are higher in the United States or in another country. This specification assumes that reversion is toward the edge of the band.

Let us rewrite equation (8) as

$$
\Delta q_{j t}^{i}=B_{j t}^{i}(\kappa, d)^{\prime} \Gamma+\varepsilon_{j t}^{i},
$$

where $B_{j t}^{i}(\kappa, d)^{\prime}$ is a $(1 \times 2)$ row vector that describes the behavior of $\Delta q_{j t}^{i}$ in the outer regime and $\Gamma$ is a $(2 \times 1)$ vector containing the autoregressive parameters to be estimated. More precisely,

$$
B_{j t}^{i}(\kappa, d)^{\prime}=\left[X^{\prime} 1\left(q_{j t-d}^{i}>\kappa\right) Y^{\prime} 1\left(q_{j t-d}^{i}<-\kappa\right)\right],
$$

where 


$$
\begin{aligned}
X^{\prime} & =\left[q_{t-1}-\kappa\right] \\
Y^{\prime} & =\left[q_{t-1}+\kappa\right]
\end{aligned}
$$

and

$$
\Gamma^{\prime}=\left[\begin{array}{ll}
\rho-1 & \rho-1
\end{array}\right]
$$

The parameters of interest are $\Gamma, \kappa$, and $d$. Equation (8) is a regression equation nonlinear in parameters that can be estimated using least squares. For given values of $\kappa$ and $d$, the least-squares estimate of $\Gamma$ is

$$
\begin{aligned}
& \hat{\Gamma}(\kappa, d)= \\
& \left(\sum_{t=1}^{T} B_{j t}^{i}(\kappa, d) B_{j t}^{i}(\kappa, d)^{\prime}\right)^{-1}\left(\sum_{t=1}^{T} B_{j t}^{i}(\kappa, d) \Delta q_{j t}^{i}\right),
\end{aligned}
$$

with residuals

$$
\hat{\varepsilon}_{j t}^{i}(\kappa, d)=\Delta q_{j t}^{i}-B_{j t}^{i}(\rho, d)^{\prime} \hat{\Gamma}(\kappa, d),
$$

and residual variance

$$
\hat{\sigma}^{2}(\kappa, d)=\frac{1}{T} \sum_{t=1}^{T} \hat{\varepsilon}_{j t}^{i}(\kappa, d)^{2} .
$$

Because the values of $\kappa$ and $d$ are not given, they should be estimated together with the autoregressive parameter, $\rho$. Hansen (1997) suggests a methodology to identify the model in equation (9) that consists of the simultaneous estimation of $\kappa$, $d$, and $\rho$ via a grid search over $\kappa$ and $d$. The model is estimated by sequential least squares for values of $d$ from 1 to 6 . The values of $\kappa$ and $d$ that minimize the sum of squared residuals are chosen. The range for the grid search is selected to contain the 15th and 85th percentiles of the threshold variable. This can be written as

$$
(\hat{\kappa}, \hat{d})=\underset{\kappa \in \Theta, d \in \Psi}{\arg \min } \hat{\sigma}^{2}(\kappa, d),
$$

where $\Theta=[\underline{\kappa}, \bar{\kappa}]$.

The least-squares estimator of $\Gamma$ is $\hat{\Gamma}=\hat{\Gamma}(\hat{\kappa}, \hat{d})$ with residuals

$$
\hat{\varepsilon}_{j t}^{i}(\hat{\kappa}, \hat{d})=\Delta q_{j t}^{i}-B_{j t}^{i}(\hat{\kappa}, \hat{d})^{\prime} \hat{\Gamma}(\hat{\kappa}, \hat{d})
$$

and residual variance

$$
\hat{\sigma}^{2}(\hat{\kappa}, \hat{d})=\frac{1}{T} \sum_{t=1}^{T} \hat{\varepsilon}_{j t}^{i}(\hat{\kappa}, \hat{d})^{2} .
$$

Testing Procedures. Before explaining the results, it is important to determine whether the TAR-type nonlinear model is superior when tested against a unit root process and against a linear AR(1) process. These tests require preestimation of both the linear model under the null hypothesis and the TAR model under the alternative.

First, we determine whether the SETAR specification is superior to a unit root process for each SRER using the Enders and Granger (1998) threshold unit root test. ${ }^{6}$ The method is a generalization of the Dickey-Fuller test. The null hypothesis is

$$
H_{0}^{A}: \rho=1
$$

against an alternative of stationarity with threshold adjustment. This test allows identification of any difference in the autoregressive parameters between the inner and outer regimes. Its main advantage is that it is generally more powerful than the Dickey-Fuller test. A failure to reject the unit root null hypothesis implies that the LOOP does not hold and prices in two locations are disconnected. We interpret this as conveying that transaction costs are so high that the entire series are included within the threshold bands. Thus, the inner and outer regimes cannot be distinguished.

When the unit root null hypothesis is rejected, we continue with our analysis. Our second step is to test a linear $\mathrm{AR}(1)$ specification against a nonlinear stationary SETAR. Let $\beta$ be the autoregressive parameter implied by the linear AR(1). The linear null hypothesis is

$$
H_{0}^{B}: \beta=\rho .
$$

${ }^{6}$ Other tests for the null hypothesis of the unit root against a nonlinear model have been proposed in the literature. Recent contributions include Kapetanios and Shin (2006) and Bec, Guay, and Guerre (2008). In particular, Kapetanios and Shin (2006) propose a Wald statistic to test a unit root null hypothesis against a threeregime SETAR process. Bec, Guay, and Guerre (2008) develop a more general procedure that consists of an adaptive threshold SupWald unit root test. We emphasize that the decision to use the Enders and Granger (1998) test does not represent a criticism of other methods. Overall, simulations have not provided evidence in favor of one test or another and this analysis is beyond the scope of our paper. 
When we find evidence of nonlinearities in the pre- and post-NAFTA periods, we determine whether the size of the threshold band is equal in both periods. Let $\tau_{j}^{i}$ be the threshold variable in the post-NAFTA period and $\theta_{j}^{i}$ be the threshold variable in the pre-NAFTA period. The null hypothesis is

$$
H_{0}^{C}: \tau_{j}^{i}=\theta_{j}^{i} .
$$

As noted in Hansen (1997), testing hypotheses $H_{0}^{B}$ and $H_{0}^{C}$ is not straightforward. A statistical problem is present because conventional tests have asymptotic nonstandard distributions. To overcome inference problems, the asymptotic distribution of the conventional $F$-statistic must be calculated using a Monte Carlo simulation. Following Hansen (1997) and Peel and Taylor (2002), if the errors are i.i.d., the null hypothesis $H_{0}^{B}$ and $H_{0}^{C}$ can be tested using the statistic

$$
F_{T}(\kappa, d)=T\left(\frac{\tilde{\sigma}^{2}-\hat{\sigma}^{2}(\kappa, d)}{\hat{\sigma}^{2}(\kappa, d)}\right),
$$

where $F_{T}$ is the $F$-statistic when $\kappa$ and $d$ are known, $T$ is the sample size, and $\hat{\sigma}^{2}(\kappa, d)$ and $\tilde{\sigma}^{2}$ are the unrestricted and restricted estimates of the residual variance, respectively. Hence, $\hat{\sigma}^{2}(\kappa, d)$ is obtained from the unconstrained nonlinear leastsquares estimation of equation (8) and $\tilde{\sigma}^{2}$ results from the estimation of equation (8) with the restriction to be tested imposed.

Because $\kappa$ and $d$ are not identified under the null hypothesis, the distribution of $F_{T}(\kappa, d)$ is not a standard chi-square distribution. Hansen (1997) shows that the asymptotic distribution of $F_{T}(\kappa, d)$ may be approximated using the following bootstrap procedure: (i) generate $y_{j,}^{i^{*}}, t=1, \ldots, T$ from i.i.d. $N(0,1)$ random draws; (ii) set $q_{j t}^{i^{*}}=y_{j t}^{i^{*}}$; (iii) using $q_{j t-1}^{i^{*}}$ for $t=1, \ldots, T$, regress $y_{j t}^{i^{*}}$ on $q_{j t-1}^{i^{*}}$ and estimate the restricted and unrestricted models and obtain the residual variances $\tilde{\sigma}^{\star 2}$ and $\hat{\sigma}^{* 2}(\kappa, d)$, respectively; (iv) with these residual variances, it is possible to calculate the following $F$-statistic:

$$
F_{T}^{*}(\kappa, d)=T\left(\frac{\tilde{\sigma}^{* 2}-\hat{\sigma}^{* 2}(\kappa, d)}{\hat{\sigma}^{* 2}(\kappa, d)}\right) .
$$

The bootstrap approximation to the asymptotic $p$-value of the test is calculated by counting the number of bootstrap samples for which $F_{T}^{*}(\kappa, d)$ exceeds the observed $F_{T}(\kappa, d)$.

\section{ESTIMATION RESULTS}

\section{Testing for Nonlinearity}

Tables $2 \mathrm{~A}, 2 \mathrm{~B}$, and $2 \mathrm{C}$ show the results of the estimation of the SETAR model for the MexicoU.S., Canada-U.S., and Mexico-Canada country pairs, respectively. The first step consists of testing the null hypothesis of a unit root using the Enders and Granger (1998) threshold unit root test. Essentially, this allows us to determine whether the autoregressive process is the same outside and inside the threshold band. A failure to reject the null hypothesis implies that the SRER is nonstationary and consequently prices in two locations are disconnected. Thus, the LOOP does not hold. Our interpretation of such a case is that transaction costs are so large that arbitrage is not profitable and the threshold band is wide enough to contain the entire time series of the SRER.

For the Mexico-U.S. country pair, the test rejects the unit root null hypothesis in half of the series for the pre-NAFTA period. By contrast, in the post-NAFTA period nonstationarity is found in four of the sectors. We interpret these results as evidence that NAFTA has been associated with greater integration between the United States and Mexico.

The behavior of relative prices between Mexico and Canada shows a similar pattern even though the degree of market integration has not improved as much in the post-NAFTA period as in the case of the United States and Mexico.

The deviations from the LOOP in the CanadaU.S. country pair show a different behavior. The unit root null hypothesis is rejected in 73 percent of the series in the pre-NAFTA period and in all the series except one in the post-NAFTA period. These results suggest that the Canadian and American markets have been more closely integrated, with a slight improvement with NAFTA.

To further test for the validity of the SETAR model, the second step consists of testing whether the nonlinear model is superior to a linear AR(1) process applying the Hansen test described pre- 
Blavy and Juvenal

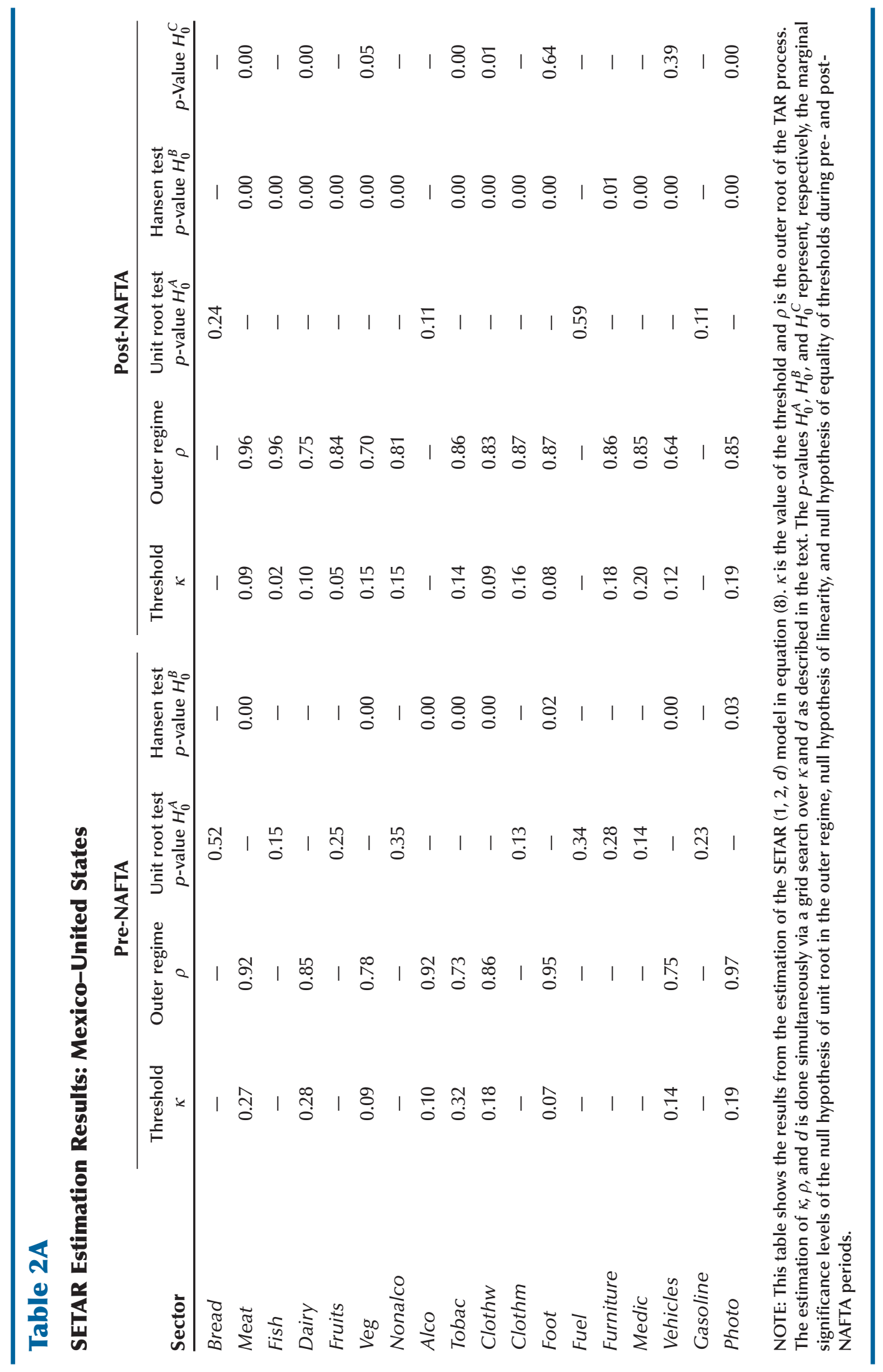




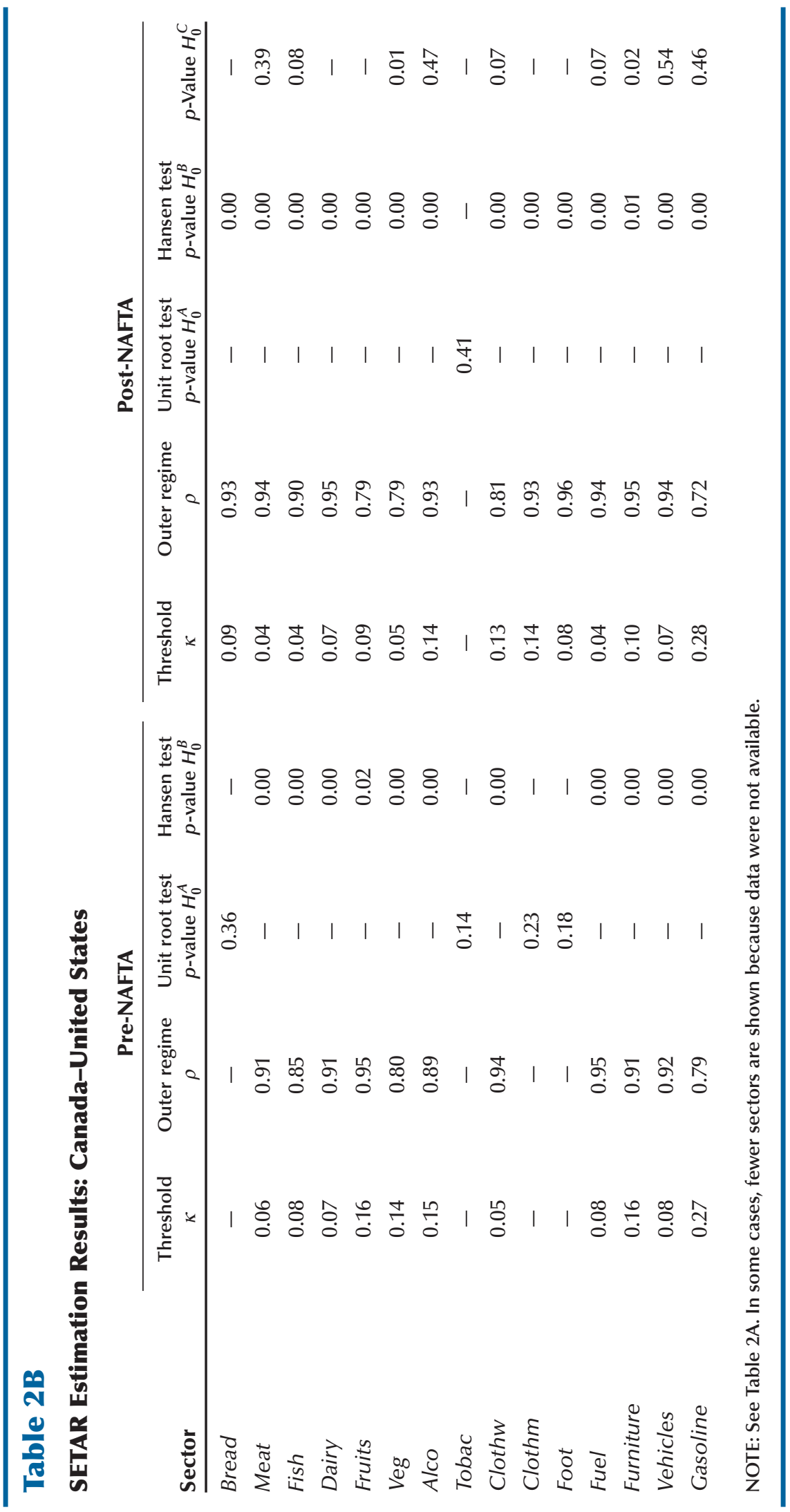




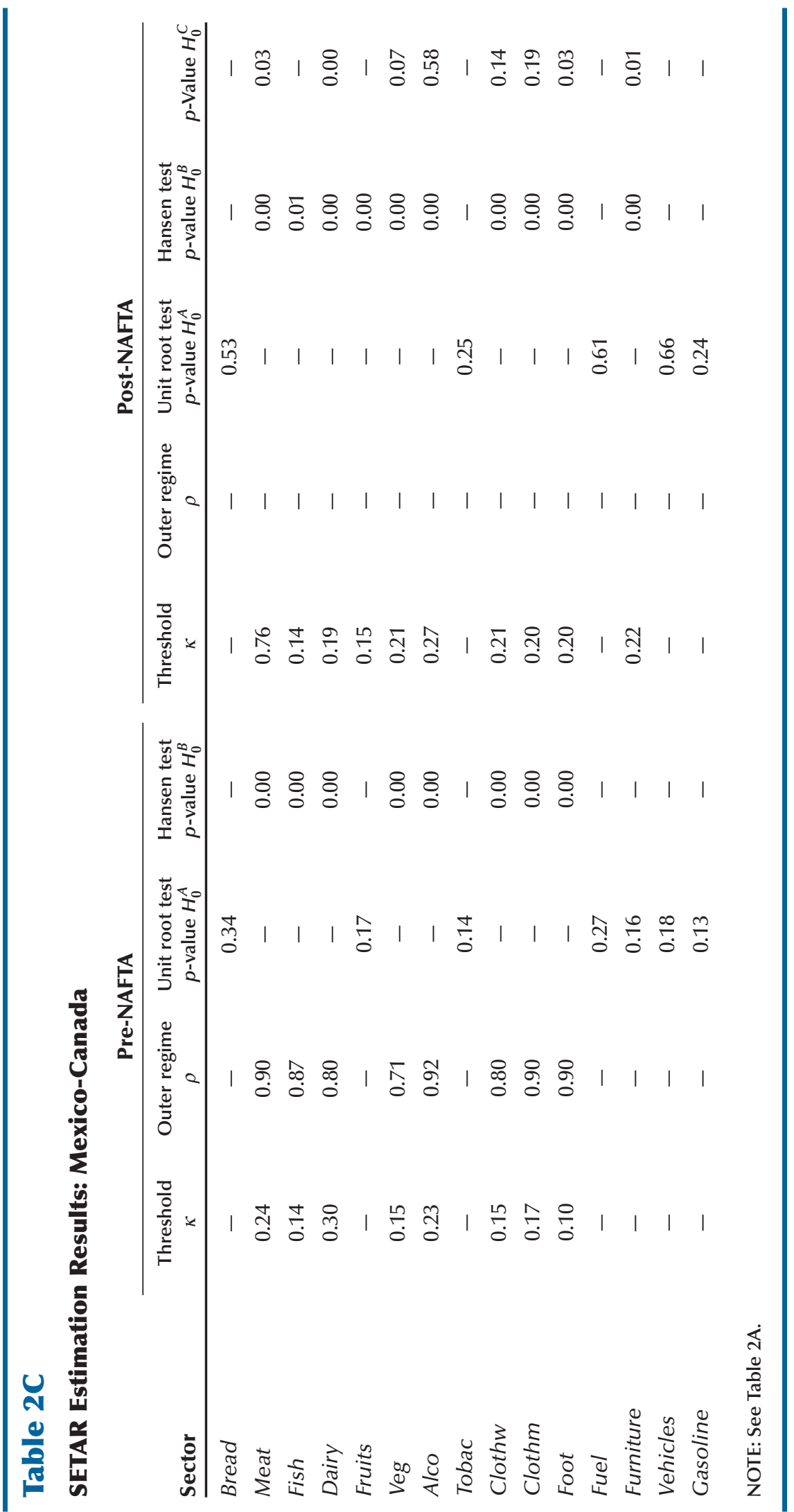


viously. We conduct this test only for cases in which the Enders and Granger (1998) test rejects the unit root null hypothesis. ${ }^{7}$ Our results show that the outcomes of the Hansen test are in line with those of the Enders and Granger (1998) test. When the Enders and Granger test finds evidence of threshold behavior, the Hansen test rejects the linear null hypothesis.

A few sectoral-level points should be highlighted. For the Mexico-U.S. country pair, the following sectors show evidence of unit root behavior: bread, a low-cost subsidized food sector; sectors subject to intervention through taxation, such as alcoholic and nonalcoholic beverages; and a sector with a high degree of differentiation, such as furniture. Interestingly, nonstationary behavior is found in sectors such as gasoline and fuel, which are characterized by a high degree of monopolistic power. Similarly, for the MexicoCanada country pair there is evidence of unit root in gasoline and bread, further suggesting the potential role of specific regulations in price differences.

In the Canada-U.S. country pair, nonstationary behavior is present in sectors subject to government intervention, such as tobacco, clothing, and footwear. By contrast, threshold adjustment is significant in food products sectors except for bread.

\section{Estimated Transaction Costs}

Tables 2A, 2B, and 2C show the estimated threshold bands for each SRER for the three country pairs. These bands are interpreted as a measure of transaction costs and thus reflect the degree of market integration.

Evidence of a strong NAFTA effect is found for the Mexico-U.S. SRERs. Transaction costs bands and the heterogeneity of the threshold values are significantly reduced after the introduction of NAFTA. In the pre-NAFTA period, they range from 7 percent (footwear) to 32 percent (tobacco). By contrast, in the post-NAFTA period, threshold values range from 2 percent (fish products) to 20 percent (medical commodities). At an indi-

\footnotetext{
7 The Hansen test requires that the series are stationary; this is why we apply this test only for the series in which the unit root null hypothesis is rejected.
}

vidual level, in sectors such as nonalcoholic beverages, clothing, furniture, and medication, transaction costs decrease from "very large" (unit root process) in the pre-NAFTA period to "measurable" with a threshold model in the postNAFTA period. In sectors that exhibit significant nonlinear behavior in both periods, threshold bands are significantly smaller in the post-NAFTA period for meat, dairy, vegetables, tobacco, women's clothing, and photo equipment. The reduction in the transaction costs bands suggests a greater market integration.

Considering those sectors in which nonlinearities are detected, average transaction costs in the Mexico-U.S. pair are smaller than those for the Mexico-Canada pair. Moreover, the latter pair shows evidence of unit root behavior in a greater number of sectors. This means that transaction costs are so high arbitrage is not worthwhile.

Transaction costs between the United States and Canada are the lowest among the three country pairs examined. Overall, average transaction costs are 34 percent higher between the United States and Mexico than between the United States and Canada. This result confirms previous evidence that the United States and Canada are the most integrated among NAFTA members. ${ }^{8}$ We also find less dispersion in the threshold bands in the pre- and post-NAFTA periods. The fact that the integration between Canada and the United States started before the introduction of NAFTA could explain this result.

A further look at sectoral characteristics confirms that highly homogeneous sectors such as fish and fruits show relatively low threshold bands. This is a standard result in the literature, reported in studies for other country pairs (see Juvenal and Taylor, 2008). Compared with the work of Juvenal

\footnotetext{
8 One possible alternative explanation for the lower thresholds between the United States and Canada than between Mexico and the United States may be that goods are more homogeneous between the first two countries. More generally, the comparability of the sectors may vary across country pairs. First, wealth effects may be at play. The relatively large income differences between Mexico and the United States and Canada affect the specific goods sampled in each CPI category. This disparity may complicate the analysis with the varying composition among luxury, middle, and ordinary products across countries. Second, statistical differences exist in the compilation of price-level data, notably in adjustments for quality changes. A solution to this problem is to look at more disaggregated price indices and SRERs.
} 


\section{Table 3A}

\section{Half-Lives: Mexico-United States}

\begin{tabular}{|c|c|c|c|c|c|c|c|c|c|c|}
\hline \multirow[b]{3}{*}{ Sector } & \multicolumn{5}{|c|}{ Pre-NAFTA } & \multicolumn{5}{|c|}{ Post-NAFTA } \\
\hline & \multicolumn{5}{|c|}{ Shock (\%) } & \multicolumn{5}{|c|}{ Shock (\%) } \\
\hline & 10 & 20 & 30 & 40 & 50 & 10 & 20 & 30 & 40 & 50 \\
\hline Bread & - & - & - & - & - & - & - & - & - & - \\
\hline Meat & 36 & 26 & 20 & 17 & 15 & 29 & 25 & 23 & 22 & 21 \\
\hline Fish & - & - & - & - & - & 19 & 18 & 18 & 18 & 18 \\
\hline Dairy & 20 & 15 & 11 & 9 & 8 & 7 & 5 & 5 & 5 & 5 \\
\hline Fruits & - & - & - & - & - & 6 & 5 & 5 & 5 & 5 \\
\hline Veg & 4 & 4 & 4 & 4 & 4 & 5 & 5 & 5 & 5 & 5 \\
\hline Nonalco & - & - & - & - & - & 7 & 7 & 6 & 6 & 6 \\
\hline Alco & 13 & 12 & 12 & 11 & 11 & - & - & - & - & - \\
\hline Tobac & 18 & 12 & 8 & 7 & 6 & 8 & 7 & 7 & 7 & 7 \\
\hline Clothw & 10 & 10 & 10 & 9 & 9 & 5 & 5 & 5 & 5 & 5 \\
\hline Clothm & - & - & - & - & - & 10 & 8 & 8 & 7 & 7 \\
\hline Foot & 18 & 17 & 16 & 16 & 16 & 6 & 6 & 6 & 6 & 6 \\
\hline Fuel & - & - & - & - & - & - & - & - & - & - \\
\hline Furniture & - & - & - & - & - & 14 & 10 & 8 & 8 & 8 \\
\hline Medic & - & - & - & - & - & 8 & 8 & 8 & 8 & 7 \\
\hline Vehicles & 6 & 5 & 5 & 4 & 3 & 6 & 4 & 4 & 4 & 4 \\
\hline Gasoline & - & - & - & - & - & - & - & - & - & - \\
\hline Photo & 55 & 49 & 44 & 40 & 37 & 24 & 14 & 10 & 9 & 8 \\
\hline Average & 20 & 17 & 14 & 13 & 12 & 11 & 9 & 8 & 8 & 8 \\
\hline
\end{tabular}

NOTE: This table shows the estimated half-lives of deviations from the LOOP for five shocks of various percentages: 10, 20, 30, 40, and 50. The half-lives were calculated conditional on average initial history using the generalized impulse response functions procedure developed by Koop et al. (1996).

and Taylor (2008), threshold bands among NAFTA members are on average slightly lower than those between the United States and European countries.

\section{Half-Lives of Relative Price Adjustment}

A usual measure of the speed of mean reversion is the half-life, which is the time required for the effect of 50 percent of a shock to die out. Tables 3A, 3B, and 3C report the estimated halflives (in terms of months) of price deviations from the LOOP for the Mexico-U.S., Canada-U.S. and Mexico-Canada SRERs. ${ }^{9}$

The speed of mean reversion is generally computed by taking into account the adjustment in the outer regime, which depends on the value of $\rho$. In this case, the half-life is calculated as if it were a linear model, that is, $\ln (0.5) / \ln (\rho)$. Lo and Zivot (2001) emphasize the uncertainty of whether the computation of half-lives for linear models is applicable for nonlinear models. However, studies based on a SETAR model generally use this measure (see, for example, Taylor, 2001). As highlighted in Juvenal and Taylor (2008), although the estimated half-lives of the outer regime yield some insights on the speed of mean reversion, this measure is limited because it does not consider the regime switching within the SETAR model.

9 We compute the half-lives only for cases in which we find evidence of threshold behavior. 
Table 3B

Half-Lives: Canada-United States

\begin{tabular}{|c|c|c|c|c|c|c|c|c|c|c|}
\hline \multirow[b]{3}{*}{ Sector } & \multicolumn{5}{|c|}{ Pre-NAFTA } & \multicolumn{5}{|c|}{ Post-NAFTA } \\
\hline & \multicolumn{5}{|c|}{ Shock (\%) } & \multicolumn{5}{|c|}{ Shock (\%) } \\
\hline & 10 & 20 & 30 & 40 & 50 & 10 & 20 & 30 & 40 & 50 \\
\hline Bread & - & - & - & - & - & 14 & 12 & 12 & 11 & 11 \\
\hline Meat & 11 & 10 & 10 & 10 & 9 & 13 & 12 & 12 & 12 & 12 \\
\hline Fish & 6 & 5 & 4 & 4 & 4 & 9 & 8 & 8 & 8 & 8 \\
\hline Dairy & 12 & 10 & 10 & 10 & 10 & 16 & 15 & 15 & 14 & 14 \\
\hline Fruits & 27 & 24 & 21 & 20 & 19 & 5 & 5 & 5 & 5 & 5 \\
\hline Veg & 7 & 6 & 6 & 6 & 6 & 5 & 5 & 5 & 5 & 5 \\
\hline Alco & 13 & 10 & 9 & 9 & 9 & 17 & 16 & 15 & 14 & 13 \\
\hline Tobac & - & - & - & - & - & - & - & - & - & - \\
\hline Clothw & 14 & 13 & 12 & 12 & 11 & 7 & 7 & 6 & 6 & 6 \\
\hline Clothm & - & - & - & - & - & 18 & 15 & 14 & 13 & 13 \\
\hline Foot & - & - & - & - & - & 25 & 22 & 20 & 20 & 19 \\
\hline Fuel & 17 & 15 & 15 & 15 & 15 & 12 & 12 & 12 & 12 & 11 \\
\hline Furniture & 21 & 15 & 13 & 12 & 12 & 29 & 24 & 21 & 19 & 18 \\
\hline Vehicles & 13 & 12 & 11 & 11 & 11 & 14 & 13 & 13 & 13 & 12 \\
\hline Gasoline & 8 & 7 & 6 & 6 & 6 & 7 & 5 & 5 & 5 & 5 \\
\hline Average & 14 & 12 & 11 & 10 & 10 & 12 & 11 & 11 & 10 & 10 \\
\hline
\end{tabular}

Thus, we compute the half-life using generalized impulse response functions proposed by Koop, Pesaran, and Potter (1996). This method considers the nonlinear nature of the SETAR model and the different adjustment speeds in the inner and outer regimes. The SETAR model exhibits an infinite half-life within the threshold band and depends on $\rho$ outside the band. A shock may cause the model to switch regimes, and this adjustment is not captured by the first methodology.

Following Taylor, Peel, and Sarno (2001), we compute the impulse response functions conditional on average initial history using Monte Carlo integration for shocks of 10, 20, 30, 40, and 50 percent. For the Mexico-U.S. pair, the average relative price adjustment is significantly faster in the post-NAFTA period. For example, for a 10 percent shock, the average pre-NAFTA half-life is 20 months, whereas the average is reduced to 11 months in the post-NAFTA period (see Table 3A). Our results also yield additional observations. In the post-NAFTA period, the speed of mean reversion varies less across different shock sizes than in the pre-NAFTA period. This suggests that relative prices adjust more quickly, independent of the size of the price shock. Half-lives vary substantially across sectors. Relative prices adjust fairly quickly for homogeneous goods, such as food products. The relative price of more highend products (e.g., furniture and photographic equipment) takes longer to adjust.

The speed of relative price adjustment in the post-NAFTA period is comparable for the MexicoU.S. and the Canada-U.S. pairs. For a 10 percent shock, the average half-lives are 11 months and 12 months, respectively. This contrasts with significant differences in the pre-NAFTA period when Mexico-U.S. relative prices were much slower to adjust than Canada-U.S. prices (see 


\section{Table 3C}

\section{Half-Lives: Mexico-Canada}

\begin{tabular}{|c|c|c|c|c|c|c|c|c|c|c|}
\hline \multirow[b]{3}{*}{ Sector } & \multicolumn{5}{|c|}{ Pre-NAFTA } & \multicolumn{5}{|c|}{ Post-NAFTA } \\
\hline & \multicolumn{5}{|c|}{ Shock (\%) } & \multicolumn{5}{|c|}{ Shock (\%) } \\
\hline & 10 & 20 & 30 & 40 & 50 & 10 & 20 & 30 & 40 & 50 \\
\hline Bread & - & - & - & - & - & - & - & - & - & - \\
\hline Meat & 24 & 17 & 13 & 12 & 11 & 7 & 6 & 6 & 6 & 6 \\
\hline Fish & 10 & 8 & 7 & 7 & 6 & 16 & 14 & 12 & 12 & 12 \\
\hline Dairy & 9 & 7 & 6 & 5 & 5 & 11 & 9 & 9 & 8 & 8 \\
\hline Fruits & - & - & - & - & - & 5 & 4 & 4 & 4 & 4 \\
\hline Veg & 4 & 4 & 4 & 4 & 4 & 5 & 4 & 4 & 4 & 4 \\
\hline Alco & 16 & 14 & 13 & 12 & 11 & 16 & 15 & 14 & 14 & 14 \\
\hline Tobac & - & - & - & - & - & - & - & - & - & - \\
\hline Clothw & 10 & 10 & 9 & 8 & 8 & 11 & 10 & 9 & 8 & 8 \\
\hline Clothm & 12 & 11 & 11 & 10 & 9 & 14 & 13 & 12 & 12 & 11 \\
\hline Foot & 9 & 8 & 8 & 8 & 7 & 15 & 13 & 12 & 12 & 11 \\
\hline Fuel & - & - & - & - & - & - & - & - & - & - \\
\hline Furniture & - & - & - & - & - & 8 & 6 & 6 & 5 & 5 \\
\hline Vehicles & - & - & - & - & - & - & - & - & - & - \\
\hline Gasoline & - & - & - & - & - & - & - & - & - & - \\
\hline Average & 12 & 10 & 9 & 8 & 8 & 11 & 10 & 9 & 9 & 9 \\
\hline
\end{tabular}

Tables 3A and 3B). The half-lives of the MexicoCanada country pairs are also less persistent in the post-NAFTA period (see Table 3C).

\section{Determinants of Thresholds}

Based on the estimates of the SETAR models, we assess whether transaction costs are related to economic variables. To do this, we estimate a regression explaining the threshold parameter obtained from the section on estimated transaction costs:

$$
\kappa=\lambda_{j}^{i}+\sum_{c=1}^{C} \Phi_{j}^{i}(c) z_{j}^{i}(c)+\varepsilon_{j}^{i},
$$

where $\kappa$ is the threshold parameter and $z_{j}^{i}$ is a vector of explanatory variables. In equation (17) we assess whether transaction costs, measured by the estimated thresholds, are explained by selected explanatory variables.
The explanatory variables are intended to capture the size and nature of transaction costs. The first variable (distance) is a proxy for shipping costs. Given the small number of country pairs and their relative proximity, distance appears to be a poor measure. Instead, we include a dummy variable that takes value 1 when countries share a common border. The second variable is the volatility of the nominal exchange rate, which intends to capture the uncertainty about the macroeconomic environment. It is measured as the standard deviation of monthly exchange rate observations. Third, we include a measure of "tradability," defined as the sum of imports and exports relative to the total output in a sector for a given country sourced from the United Nations Industrial Development Organization (UNIDO) database. Fourth, we use the number of establishments in each sector as a proxy for competition, or concentration, obtained from the UNIDO data- 


\section{Table 4}

\section{Threshold Regressions}

\begin{tabular}{lcc} 
Variables & $\mathbf{( 1 )}$ & $\mathbf{( 2 )}$ \\
\hline Distance & -0.042 & -0.036 \\
& $(0.054)^{*}$ & $(0.058)^{*}$ \\
Dummy post-NAFTA & -0.105 & -0.111 \\
& $(0.002)^{* *}$ & $(0.001)^{* *}$ \\
Exchange rate volatility & 4.468 & 4.266 \\
& $(0.000)^{* * *}$ & $(0.000)^{* * *}$ \\
Firms & -0.002 & - \\
& $(0.477)$ & - \\
Tradability & -0.045 & - \\
& $(0.259)$ & - \\
$R^{2}$ & 0.34 & 0.33 \\
$N$ & 89 & 89
\end{tabular}

NOTE: This table shows the results from the estimation of equation (17); $p$-values are shown in parentheses. ${ }^{*}, * *$, and ${ }^{* * *}$ denote significance at the 10,5 , and 1 percent levels, respectively.

base. Finally, a dummy for the post-NAFTA period is included.

We examine the determinants of thresholds for the entire sample, including all three country pairs. ${ }^{10,11}$ The results, shown in Table 4 , indicate that three variables are significant: the post-

NAFTA dummy, the shared border, and nominal exchange rate volatility. These variables are significant in all specifications. We find that the thresholds are lower when countries share a border. Nominal exchange rate volatility is also significant. This indicates that uncertainty about the macroeconomic environment limits arbitrage. The post-NAFTA dummy is also highly significant: The negative coefficient indicates that the introduction of NAFTA is associated with lower transaction costs. Neither the number of firms in a sector nor the degree of "tradability" in a sector is statistically significant (column 1 in Table 4). ${ }^{12}$

\footnotetext{
${ }^{10}$ Because we cannot obtain data on firms and tradability disaggregated for clothing (women) and clothing (men) but for only a generic clothing sector, we consider the average threshold value of clothing (women) and clothing (men) as the $\hat{\kappa}$ value for clothing.

${ }^{11}$ When we find evidence of unit root behavior in deviations from the LOOP, we consider $\kappa$ to be the highest value of the threshold variable in the grid search. This implies that transaction costs are so high that the entire SRER series is within the threshold band.
}

In column 2, these two variables are excluded with little change in the results.

Overall, thresholds appear to be determined by distance (border) and exchange rate volatility. These results are consistent with findings in the literature. For example, Imbs et al. (2003) find that distance and exchange rate volatility explain the threshold values.

Another strand of the literature analyzed the determinants of relative price differentials between the United States and Canada using different types of models. Our results are consistent with the findings of these studies. As an example, Engel and Rogers (1996) study the nature of deviations from the LOOP using CPI data for 14 goods sectors for different U.S. and Canadian cities. This study shows that the Canadian and U.S. markets are not perfectly integrated and that distance and border are major determinants of price differences. In a related study, Engel et al. (2005) investigate the LOOP between U.S. and Canadian cities using actual prices (instead of price indices). They find that absolute price differences between U.S. and Canadian prices are higher than 7 percent. In addition, their results show border plays a significant role in explaining price differentials between cities.

\section{ROBUSTNESS OF RESULTS}

We conduct three robustness checks to gauge the sensitivity of empirical results to underlying assumptions and variable definitions. First, we consider the possibility of long-run trends in the measured price differentials arising from aggregation issues in price indices or the presence of nontradable components or quality differences. We define $q_{j t}^{i}$ as the detrended and demeaned component of the price difference, $x_{j t}^{i}$, given by $x_{j t}^{i}=+c_{j}^{i}+\theta t+q_{j t}^{i}$. As described previously, it is estimated as an OLS residual.

Overall, our baseline findings prove robust to using detrended SRERs instead of the demeaned series. Tables 5A, 5B, and 5C show the results of the estimation of the SETAR model with detrended

\footnotetext{
${ }^{12}$ Poor data quality is a probable explanation for the lack of significance.
} 


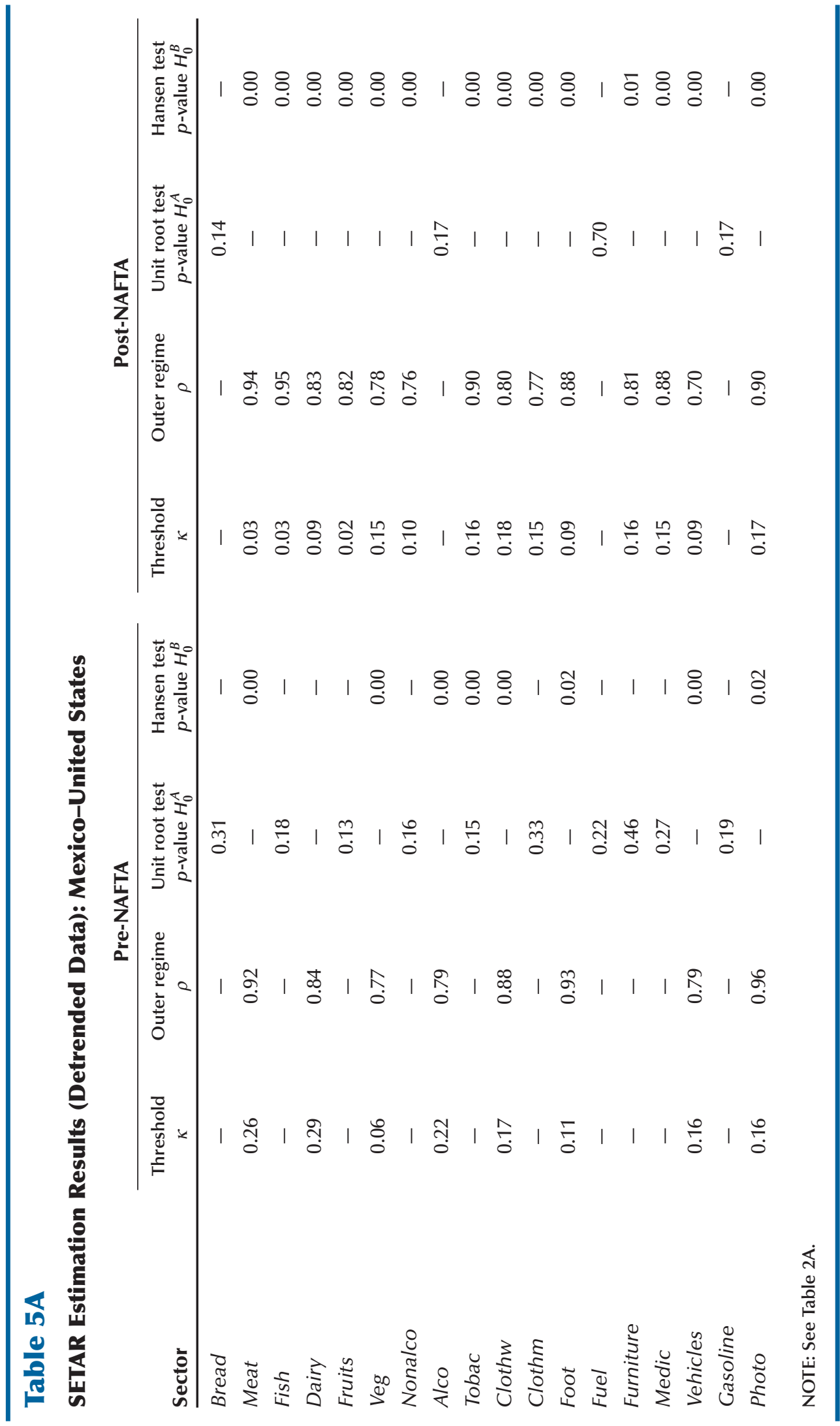




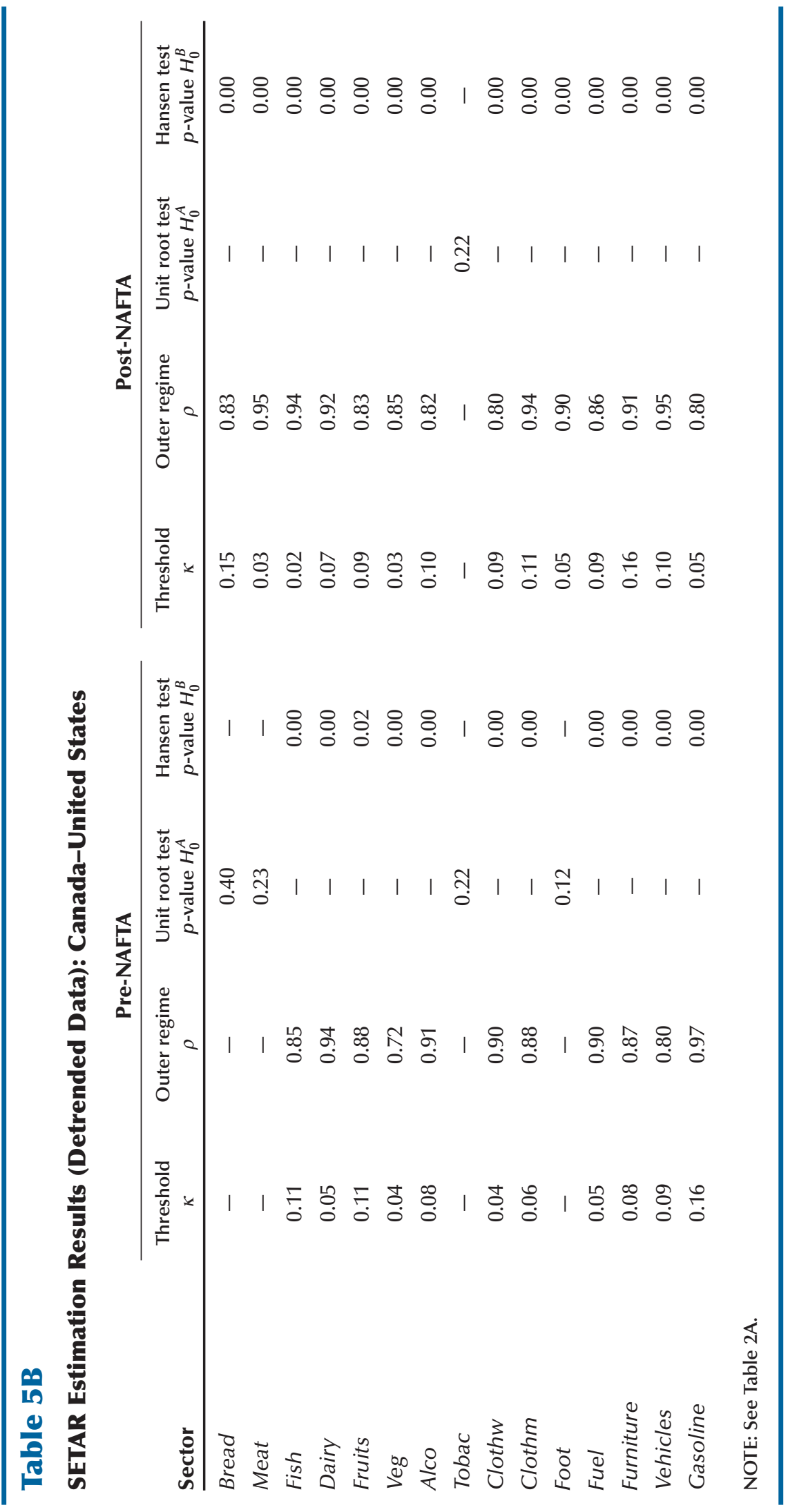




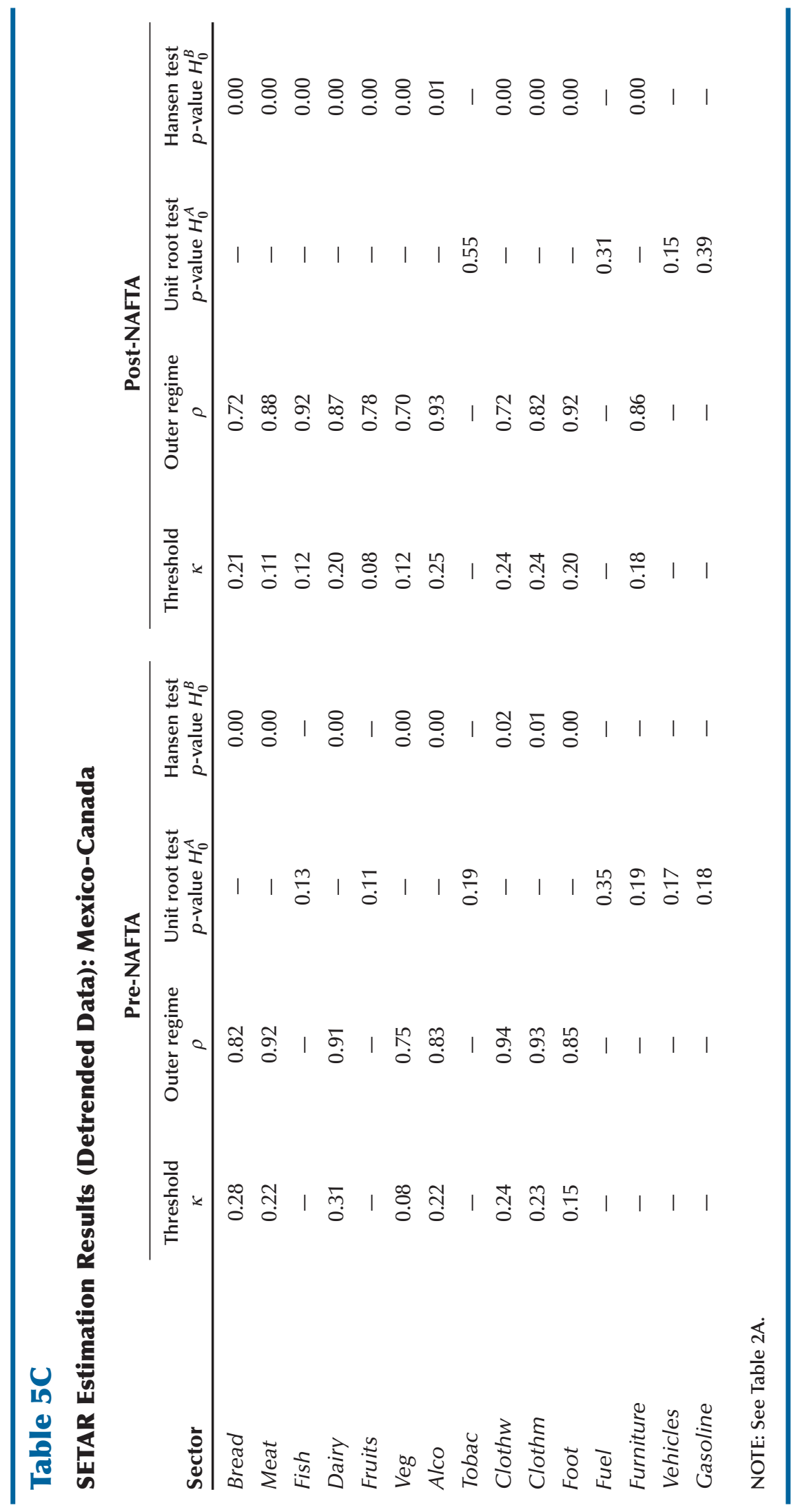


Table 6A

SETAR Estimation Results (Different Mean during Tequila Crisis): Mexico-United States

\begin{tabular}{lcccc} 
& \multicolumn{3}{c}{ Post-NAFTA } \\
\cline { 2 - 5 } Sector & $\begin{array}{c}\text { Threshold } \\
\kappa\end{array}$ & $\begin{array}{c}\text { Outer regime } \\
\rho\end{array}$ & $\begin{array}{c}\text { Unit root test } \\
p \text {-value } H_{0}^{A}\end{array}$ & $\begin{array}{c}\text { Hansen test } \\
p \text {-value } H_{0}^{B}\end{array}$ \\
\hline Bread & - & - & 0.54 & - \\
Meat & 0.14 & 0.82 & - & 0.00 \\
Fish & 0.13 & 0.91 & - & 0.00 \\
Dairy & 0.07 & 0.71 & - & 0.00 \\
Fruits & 0.05 & 0.77 & - & 0.00 \\
Veg & 0.04 & 0.83 & - & 0.00 \\
Nonalco & 0.14 & 0.78 & - & 0.00 \\
Alco & 0.11 & 0.93 & - & 0.00 \\
Tobac & 0.08 & 0.89 & - & 0.00 \\
Clothw & 0.09 & 0.83 & - & 0.00 \\
Clothm & 0.10 & 0.79 & - & 0.00 \\
Foot & 0.08 & 0.94 & - & 0.00 \\
Fuel & 0.14 & 0.75 & - & 0.00 \\
Furniture & 0.11 & 0.90 & - & 0.00 \\
Medic & 0.17 & 0.77 & 0.25 & 0.00 \\
Vehicles & 0.12 & 0.83 & - & 0.00 \\
Gasoline & - & - & & - \\
Photo & - & 0.91 & & 0.00 \\
NOTE: See Table 2 A. & 0.12 & & & \\
\hline
\end{tabular}

SRERs. The conceptual problem with including a trend in the real exchange rate is that it implies that the real exchange rate converges to a different mean across time. This implication is somewhat contradictory to the LOOP. Hence, our preferred measure is the demeaned series. The stability of our results with the different measures indicates that the trend component may not be of the utmost importance.

Second, we test the sensitivity of the results to a structural break in the Mexican series over the study period (1980-2006) during the Tequila Crisis. The results reported herein assume a constant mean over the period, consistent with the LOOP hypothesis. However, as a robustness check, we also test the sensitivity of the results to two conditions: (i) allowing for a different mean over the Tequila Crisis (1994:12-1995:12) and (ii) restricting the estimation period to 1996-2006. This was intended to assess whether the Tequila Crisis would significantly affect our findings. Our baseline findings are again robust to these checks. Tables 6A, 6B, and 6C report the estimated thresholds for each SRER, allowing for a different mean for the real exchange rate during the Tequila Crisis. Across sectors, homogeneous goods have lower transaction costs than other goods in the sample. Across country pairs, average transaction costs among NAFTA members are 27 percent higher between the United States and Mexico than between the United States and Canada, slightly less than the results when the Tequila Crisis is ignored. The results of the latter robustness analysis (not reported here but available upon request) are broadly consistent with the ones discussed here; thus, the Tequila Crisis does not significantly affect our findings. 


\section{Table 6B}

SETAR Estimation Results (Different Mean during Tequila Crisis): Canada-United States

\begin{tabular}{|c|c|c|c|c|}
\hline \multirow[b]{2}{*}{ Sector } & \multicolumn{4}{|c|}{ Post-NAFTA } \\
\hline & $\begin{array}{c}\text { Threshold } \\
\kappa \\
\end{array}$ & $\begin{array}{c}\text { Outer regime } \\
\rho\end{array}$ & $\begin{array}{c}\text { Unit root test } \\
p \text {-value } H_{0}^{A}\end{array}$ & $\begin{array}{l}\text { Hansen test } \\
p \text {-value } H_{0}^{B}\end{array}$ \\
\hline Bread & 0.09 & 0.93 & - & 0.00 \\
\hline Meat & 0.04 & 0.94 & - & 0.00 \\
\hline Fish & 0.04 & 0.90 & - & 0.00 \\
\hline Dairy & 0.07 & 0.95 & - & 0.00 \\
\hline Fruits & 0.09 & 0.79 & - & 0.00 \\
\hline Veg & 0.05 & 0.79 & - & 0.00 \\
\hline Alco & 0.14 & 0.93 & - & 0.00 \\
\hline Tobac & 0.05 & 0.95 & - & 0.03 \\
\hline Clothw & 0.13 & 0.81 & - & 0.00 \\
\hline Clothm & 0.14 & 0.93 & - & 0.00 \\
\hline Foot & 0.08 & 0.96 & - & 0.00 \\
\hline Fuel & 0.04 & 0.94 & - & 0.00 \\
\hline Furniture & 0.10 & 0.95 & - & 0.00 \\
\hline Vehicles & 0.07 & 0.94 & - & 0.00 \\
\hline Gasoline & 0.26 & 0.72 & - & 0.00 \\
\hline
\end{tabular}

\section{CONCLUSION}

Using a SETAR model, we find strong evidence of nonlinearities in SRER dynamics across Mexico, Canada, and the United States in the preand post-NAFTA periods. This result is consistent with the predictions of theoretical models that incorporate some form of market segmentation. Overall, mean reversion occurs when deviations from the LOOP are significant and the benefits of arbitrage are higher than transaction costs.

We obtain two key parameters from the estimation of SETAR models. The first parameter is the threshold, taken as a measure of transaction costs. The second parameter is the autoregressive parameter in the outer regime, which determines the speed of mean reversion. We obtain these parameters for each SRER corresponding to the three country pairs for both periods.

Our findings indicate that the value of transaction costs is highly heterogeneous for different sectors and countries. The estimated price thresholds range from 2 percent to 32 percent for the Mexico-U.S. and Canada-U.S. country pairs. The results generally confirm that highly homogeneous sectors, such as fish and fruits, show low threshold bands. Overall, average transaction costs among NAFTA members are 34 percent higher between the United States and Mexico than between the United States and Canada. This indicates that Mexico and the United States are relatively less integrated than Canada and the United States. In turn, threshold bands are higher for the Mexico-Canada pair.

We relate the value of the threshold band to plausible economic determinants. Our results show that the border effect and exchange rate volatility are significant determinants of transaction costs. The dummy post-NAFTA is also strongly significant and negative, confirming that the introduction of NAFTA is associated with lower transaction costs. 
Table 6C

SETAR Estimation Results (Different Mean during Tequila Crisis): Mexico-Canada

\begin{tabular}{lcccc} 
& \multicolumn{4}{c}{ Post-NAFTA } \\
\cline { 2 - 5 } Sector & $\begin{array}{c}\text { Threshold } \\
\kappa\end{array}$ & $\begin{array}{c}\text { Outer regime } \\
\rho\end{array}$ & $\begin{array}{c}\text { Unit root test } \\
p \text {-value } H_{0}^{A}\end{array}$ & $\begin{array}{c}\text { Hansen test } \\
p \text {-value } H_{0}^{B}\end{array}$ \\
\hline Bread & - & - & 0.74 & - \\
Meat & 0.20 & 0.92 & - & 0.00 \\
Fish & 0.13 & 0.91 & - & 0.00 \\
Dairy & 0.08 & 0.97 & - & 0.05 \\
Fruits & 0.08 & 0.83 & - & 0.00 \\
Veg & 0.04 & 0.80 & - & 0.00 \\
Alco & 0.06 & 0.95 & - & 0.02 \\
Tobac & - & - & - & - \\
Clothw & 0.10 & 0.90 & - & 0.00 \\
Clothm & 0.11 & 0.89 & - & 0.00 \\
Foot & 0.06 & 0.95 & - & 0.02 \\
Fuel & 0.14 & 0.77 & 0.16 & 0.01 \\
Furniture & - & - & 0.13 & - \\
Vehicles & - & - & 0.07 & - \\
Gasoline & - & - & & - \\
NOTE: See Table 2A. & & & & - \\
\hline
\end{tabular}

To shed some light on the mean-reverting properties of the SRERs, we consider the regime switching that occurs inside and outside the band in the SETAR model and compute the half-lives using generalized impulse response functions. Overall, the speed of mean reversion depends on the size of the shock. Larger shocks mean-revert much faster than smaller ones. On average, the half-lives are substantially reduced after the introduction of NAFTA. For the Mexico-U.S. country pair, the average half-life is reduced from 20 months in the pre-NAFTA period to 11 months in the post-NAFTA period. The post-NAFTA period shows less variation in the speed of mean reversion across different shock sizes than in the pre-NAFTA period.

Our analysis therefore supports the arguments that (i) emerging markets-in this case, Mexicostill face higher transaction costs than their developed counterparts and (ii) trade liberalization may help in lower relative price differentials between countries. We suspect that lack of competition may be a major determinant of high price thresholds but cannot prove this matter empirically.

The main conclusion of our analysis is that Mexico has made progress but still has considerable room for improvement in reducing barriers to goods market integration and achieving the full benefits of globalization. Future research should focus on why transactions costs between Mexico and the United States continue to exceed those between Canada and the United States for many types of goods and whether these costs can be reduced through policy actions. Examples of such actions include developing logistics, transportation, and internal distribution mechanisms or enhancing the state of competition among domestic firms and reducing remaining barriers to external trade. 


\section{REFERENCES}

Bec, Frédérique; Guay, Alain and Guerre, Emmanuel. "Adaptive Consistent Unit-Root Tests Based on Autoregressive Threshold Model." Journal of Econometrics, January 2008, 142(1), pp. 94-133.

Balke, Nathan S. and Fomby, Thomas B. "Threshold Cointegration.” International Economic Review, August 1997, 38, pp. 627-45.

Dumas, Bernard. "Dynamic Equilibrium and the Real Exchange Rate in a Spatially Separated World.” Review of Financial Studies, June 1992, 5(2), pp. 153-80.

Enders, Walter and Granger, C.W.J. "Unit-Root Tests and Asymmetric Adjustment with an Example Using the Term Structure of Interest Rates." Journal of Business and Economic Statistics, July 1998, 16, pp. 304-12.

Engel, Charles and Rogers, John H. "How Wide Is the Border?" American Economic Review, December 1996, 86(5), pp. 1112-25.

Engel, Charles; Rogers, John H. and Wang, Shing-Yi. "Revisiting the Border: An Assessment of the Law of One Price Using Very Disaggregated Consumer Price Data," in Rebecca Driver; Peter Sinclair and Christoph Thoenissen, eds., Exchange Rates, Capital Flows and Policy. London: Routledge, 2005, pp. 187-203.

Giovannini, Alberto. "Exchange Rates and Traded Goods Prices." Journal of International Economics, February 1988, 24(1-2), pp. 45-68.

González, Marco and Rivadeneyra, Francisco. "La Ley de un Solo Precio en México: Un Análisis Empírico.” Gaceta de Economía, 2004, 19, pp. 91-115.

Hansen, Bruce E. "Inference When a Nuisance Parameter Is Not Identified under the Null Hypothesis.” Econometrica, March 1996, 64, pp. 413-30.

Hansen, Bruce E. "Inference in TAR Models." Studies in Nonlinear Dynamics and Econometrics, April 1997, 2(1), pp. 1-14.
Heckscher, Eli F. "Växelkurens Grundval vid Pappersmynfot." Economisk Tidskrift, 1916, 18(10), pp. 309-12.

Imbs, Jean; Mumtaz, Haroon; Ravn, Morten O. and Rey, Hélène. "Nonlinearities and Real Exchange Rate Dynamics." Journal of the European Economic Association, April 2003, 1(2-3), pp. 639-49.

Isard, Peter. "How Far Can We Push the Law of One Price?" American Economic Review, December 1977, 67(5), pp. 942-48.

Juvenal, Luciana and Taylor, Mark P. “Threshold Adjustment of Deviations from the Law of One Price." Studies in Nonlinear Dynamics and Econometrics, September 2008, 12(3), Article 8.

Kapetanios, George and Shin, Yongcheol. "Unit Root Tests in Three-Regime SETAR Models.”

Econometrics Journal, June 2006, 9(2), pp. 252-78.

Koop, Gary; Pesaran, M. Hashem and Potter, Simon M. "Impulse Response Analysis in Nonlinear Multivariate Models.” Journal of Econometrics, September 1996, 74(1), pp. 119-47.

Lo, Ming Chien and Zivot, Eric. "Threshold Cointegration and Nonlinear Adjustment to the Law of One Price." Macroeconomic Dynamics, September 2001, 5(4), pp. 533-76.

Obstfeld, Maurice and Taylor, Alan M. "Nonlinear Aspects of Goods-Market Arbitrage and Adjustment: Heckscher's Commodity Points Revisited." Journal of Japanese and International Economics, December 1997, 11(4), pp. 441-79.

O’Connell, Paul G.J. "The Overvaluation of the Purchasing Power Parity." Journal of International Economics, February 1998, 44(1), pp. 1-19.

Peel, David A. and Taylor, Mark P. "Covered Interest Rate Arbitrage in the Interwar Period and the Keynes-Einzig Conjecture." Journal of Money, Credit, and Banking, February 2002, 34(1), pp. 51-75.

Richardson, J. David. "Some Empirical Evidence on Commodity Arbitrage and the Law of One Price." Journal of International Economics, May 1978, 8(2), pp. 341-51. 


\section{Blavy and Juvenal}

Sarno, Lucio; Taylor, Mark P. and Chowdhury, Ibrahim. "Nonlinear Dynamics in Deviations from the Law of One Price: A Broad-Based Empirical Study." Journal of International Money and Finance, February 2004, 23(1), pp. 1-25.

Sercu, Piet and Uppal Raman. "The Exchange Rate in the Presence of Transaction Costs: Implications for Tests of Purchasing Power Parity." The Journal of Finance, September 1995, 50(4), pp. 1309-319.

Taylor, Alan M. "Potential Pitfalls for the PurchasingPower-Parity Puzzle? Sampling and Specification Biases in Mean-Reversion Tests of the Law of One Price.” Econometrica, March 2001, 69(2), pp. 473-98.

Taylor, Mark P.; Peel, David A. and Sarno, Lucio. "Nonlinear Mean-Reversion in Real Exchange Rates: Towards a Solution to the Purchasing Power Parity Puzzles." International Economic Review, November 2001, 42(4), 1015-42.

Tong, Howell. Nonlinear Time Series: A Dynamic System Approach. Oxford, UK: Clarendon Press, July 1993. 